\title{
Senescence and apoptosis in carcinogenesis of cervical squamous carcinoma
}

\author{
Wei Feng ${ }^{1}$, Jianguo Xiao ${ }^{1}$, Zhihong Zhang ${ }^{2}$, Daniel G Rosen ${ }^{2}$, Robert E Brown ${ }^{1}$, Jinsong Liu ${ }^{2}$ \\ and Xiuzhen Duan ${ }^{1}$ \\ ${ }^{1}$ Department of Pathology, The University of Texas Medical School at Houston, Houston, TX, USA \\ and ${ }^{2}$ Department of Pathology, The University of Texas MD Anderson Cancer Center, Houston, TX, USA
}

\begin{abstract}
Senescence and apoptosis are two key mechanisms that protect against cancer development. Many cell cycle regulators, such as $\mathrm{p} 14^{\mathrm{ARF}}, \mathrm{p} 15^{\mathrm{INK} 4 \mathrm{~b}}$ and $\mathrm{p} 16^{\mathrm{INK} 4 \mathrm{a}}$, are important in $\mathrm{G} 1$ cell cycle arrest and oncogene-induced senescence. The bcl-2 protein is one of the key components that control apoptosis, while the p53 protein plays key roles in both mechanisms. The genes of these key regulator proteins are often mutated or deleted in various malignancies. It is unknown how senescence and apoptosis are regulated in one of the most common tumors of the female genital tract, cervical squamous cell carcinoma (SCC). In this study the, expression of senescence, apoptosis and proliferation markers in normal cervical epithelium, cervical intraepithelial neoplasia (CIN) and SCC are characterized via immunohistochemical staining for p14 ${ }^{\mathrm{ARF}}$, p15 ${ }^{\mathrm{INK} 4 \mathrm{~b}}$, p16 ${ }^{\mathrm{INK} 4 \mathrm{a}}$, bcl-2, p53 and Ki-67 in tissue microarray blocks containing 20 samples each of normal cervix, moderate-to-severe cervical dysplasia (CIN II-III) and invasive SCC. Samples are derived from 60 total cases of cervical biopsies and cervical conizations. Results showed that the proliferation marker, $\mathrm{Ki}-67$, is markedly increased, and the senescence markers, $\mathrm{p} 15^{\mathrm{INK} 4 \mathrm{~b}}, \mathrm{p} 16^{\mathrm{INK} 4 \mathrm{a}}$ and $\mathrm{p} 14^{\mathrm{ARF}}$ are overexpressed in both dysplasia and carcinoma. P53 immunostain is negative in all normal cervical tissue, and positive in dysplasia and carcinoma. Although the expression of bcl-2 is increased in dysplasia, this marker is negative in approximately half of SCC cases. These results suggest that some senescence pathways are activated and are still maintained in cervical dysplasia and carcinoma. However proliferation is increased and carcinogenesis is not thwarted, leading to eventual development of cervical cancer. Other mechanisms, such as those that account for the apparent overexpression of p53 and paradoxical loss of bcl-2 expression in some SCC cases, as well as additional senescence and apoptotic pathways, may play key roles carcinogenesis of cervical SCC.
\end{abstract}

Modern Pathology (2007) 20, 961-966; doi:10.1038/modpathol.3800927; published online 13 July 2007

Keywords: senescence; apoptosis; carcinogenesis; cervical squamous; carcinoma

Squamous cell carcinoma (SCC) of the uterine cervix is the second most common malignant tumor of the female genital tract. It is well known that the human papilloma virus (HPV) is the single most important etiologic agent in the pathogenesis of cervical carcinoma. However, not all women who are infected with the high-risk HPV (HPV subtypes 16 and 18) develop cervical carcinoma. It often takes years or decades before persistent dysplasia eventually develops into invasive cervical SCC. This suggests that other cofactors must be present in the pathogenic pathway between cervical dysplasia (CIN) and carcinoma.

Correspondence: Dr W Feng, MD, Department of Pathology and Laboratory Medicine, Houston Medical School, University of Texas, 6431 Fannin Street, MSB 2.262, Houston, TX 77030, USA. E-mail: Wei.Feng@uth.tmc.edu

Received 26 November 2006; revised 29 May 2007; accepted 05 June 2007; published online 13 July 2007
There are two basic cellular mechanisms by which cells with accumulated somatic mutations are prevented from cancer development: apoptosis and senescence. Senescence is a form of growtharrested state described first in cultured fibroblasts where metabolically active cells undergo stable cell cycle arrest at the G1 phase. $^{1-4}$ This is induced by a variety of stresses and is thought to be a mechanism by which potential cancer cells that harbor oncogenic mutations are prevented from further replication and development into a full-fledged cancer. Cell cycle regulators such as those within the retinoblastoma (Rb) and p53 pathways are the gate keepers that maintain the senescence program. It is well known that the E6 and E7 oncoproteins of high-risk HPVs, bind respectively to the p53 and Rb tumor suppressor proteins. This is thought to be the mechanism by which HPV interferes with normal cell cycle control and initiates malignant transformation. 
The regulatory proteins involved in the $\mathrm{pRb}$ (retinoblastoma protein) and p53 pathways are cyclin-dependent kinases (CDKs) and cyclin-dependent kinase inhibitors (CDKIs). Among the CDKIs, $\mathrm{p} 14^{\mathrm{ARF}}, \mathrm{p} 15^{\mathrm{INK} 4 \mathrm{~b}}$ and $\mathrm{p} 16^{\mathrm{INK} 4 \mathrm{a}}$ have been identified to be important in maintaining senescence. ${ }^{1}$ p16 negatively regulates the cell cycle through competitive binding of CDK 4 and 6 , thereby inhibiting their binding to cyclin D1. CDKs 4 and 6 regulate the G1 checkpoint via CDK/cyclin-D phosphorylation of the $\mathrm{pRb}$. Once the $\mathrm{pRb}$ is phosphorylated, the cell is allowed to pass through the G1 phase onto the S phase $^{5,6}$ The p $16^{\mathrm{INK} 4 \mathrm{a}}$ gene is frequently inactivated in a variety of human tumors. ${ }^{7}$ p $14^{\mathrm{ARF}}$ is a protein encoded by the same CDKN2a gene which encodes p16 ${ }^{\text {INK4a }}$. It negatively regulates the cell cycle at G1/S and G2/M by inhibiting the MDM2 oncoprotein, thereby blocking the MDM2-mediated breakdown of $\mathrm{p} 53 .{ }^{8}$ Another negative growth regulator is $\mathrm{p} 15^{\mathrm{INK} 4 \mathrm{~b}}$ which is a downstream effecter of transforming growth factor $\beta$-induced cell cycle arrest. ${ }^{1}$

The other anti-cancer cellular mechanism is apoptosis. The bcl-2 oncoprotein, which is localized to the inner mitochondrial membrane, is known to inhibit apoptosis. ${ }^{9}$ The bcl-2 oncogene is activated as a consequence of the $t(14 ; 18)$ chromosomal translocation in human follicular lymphomas. Its overexpression may prolong potential cancer cells survival and allow for malignant transformation..$^{10,11}$ The p53 protein plays a hand in both senescence and apoptosis pathways. It can induce senescence via activation of the CDKI, p21. On the other hand, it can also induce apoptosis via activation of the bcl-2 antagonist, BAX.

Recently, p14 ${ }^{\mathrm{ARF}}, \mathrm{p} 15^{\mathrm{INK} 4 \mathrm{~b}}$ and $\mathrm{p} 16^{\mathrm{INK} 4 \mathrm{a}}$ have been identified as senescence markers and are positive in pre-malignant lung lesions, but not in malignant lung tumors. ${ }^{1}$ To date, different studies of cervical carcinomas have reported conflicting results of the expression of these senescence markers as well as anti-apoptosis marker bcl-2. ${ }^{9,12-17}$ The purpose of this study was to characterize the expression of $\mathrm{p} 14^{\mathrm{ARF}}, \mathrm{p} 15^{\mathrm{INK} 4 \mathrm{~b}}, \mathrm{p} 16^{\mathrm{INK} 4 \mathrm{a}} \mathrm{ki}-67, \mathrm{p} 53$ and bcl-2 during the development cervical cancer by using the immuno-peroxidase technique in tissue microarrays containing cases of normal cervix, cervical intraepithelial neoplasia (CIN) and invasive cervical squamous carcinoma.

\section{Materials and methods}

The pathology database at Lyndon B Johnson Hospital was retrospectively reviewed and total of 60 cases of normal cervix, cervical dysplasia (cervical intraepithelial lesion, CIN) and invasive cervical SCC were selected. All identifiers were removed to protect patient's confidentiality. Three tissue microarray blocks containing 20 tissue sample of normal cervix, cervical dysplasia (cervical intraepithelial lesion, CIN) and invasive cervical SCC were created by manually re-embedding archived paraffin-embedded tissues.

\section{Immunohistochemical Staining}

After initial deparaffinization, sections were steamed in $10 \mathrm{mM}$ citrate buffer ( $\mathrm{pH}$ 6.0) to unmask the epitopes for $20 \mathrm{~min}$ and then treated with protein-blocking solution (Biocare Medical, Walnut Creek, CA, USA) for $10 \mathrm{~min}$. Tissue microarray slides were subjected to immunohistochemical staining and were incubated against $\mathrm{p} 16^{\mathrm{INK} 4 \mathrm{a}}$ (Biocare Medical; 1:100 for $30 \mathrm{~min}$ at ambient temperature), p14 ${ }^{\mathrm{ARF}}$ (1 $\mathrm{h}$ at ambient temperature; GeneTex prediluted, San Antonio, TX, USA), p15 ${ }^{\text {INK4b }}$ (1:300 for $1 \mathrm{~h}$ at ambient temperature; Santa Cruz, Santa Cruz, CA, USA), Ki-67 (DAKO, 1:500), Bcl-2 (1:250 overnight at 41C; Stressgen, San Diego, CA, USA) and p53-DO1 (Novocastra, 1:50). Slides were incubated with universal secondary antibody (Biocare Medical) and horseradish peroxidase (Biocare Medical) for $15 \mathrm{~min}$ each. Tissues were stained for $3 \mathrm{~min}$ with freshly prepared three, 30-diaminobenzidine tetrahydrochloride and then counterstained with hematoxylin, dehydrated and mounted.

\section{Tissue Microarray Analysis}

Two pathologists visually read the tissue array under the microscope and scored each core individually. Cases in which no epithelial cells were found or no core was available were excluded. Protein expression was semiquantified with regard to the intensity of cell staining graded as $0-3+{ }^{('} 0$ ' for negative staining if there is total absence; score of ' 1 ', ' 2 ' or ' 3 ' in order of ascending strength of positive staining), as well as the percentage (ranging from 0 to $100 \%$ ) of CIN or SCC lesion (percent of entire squamous epithelium is used for the normal cases) with positive staining of any intensity ranging from 1 to 3 . Resulting staining intensity scores and percentage of positive staining are averaged between the two pathologists.

\section{Results}

The expressions of $\mathrm{p} 14^{\mathrm{ARF}}, \mathrm{p} 15^{\mathrm{INK} 4 \mathrm{~b}}, \mathrm{p} 16^{\mathrm{INK} 4 \mathrm{a}}, \mathrm{P} 53$ and Ki-67 are predominantly within the nucleus, while the expression of bcl-2 is predominantly within the cytoplasm of the cervical epithelial cells. Overall, p16 ${ }^{\mathrm{INK} 4 \mathrm{a}}$ and p53 showed almost complete negative expression within normal cervical epithelium, where as all other markers examined showed some degree of positive expression within the basal or parabasal cells.

The $\mathrm{p} 16^{\mathrm{INK} 4 \mathrm{a}}$ expression is negative in normal cervical epithelium and positive in the majority of CIN and SCC cases. Its staining in 17/20 CIN and 15/ 20 SCC specimens are diffuse and strong $(2-3+$; 
Normal

Cervix
Cervical

Dysplasia
Invasive

Squamous Carcinoma

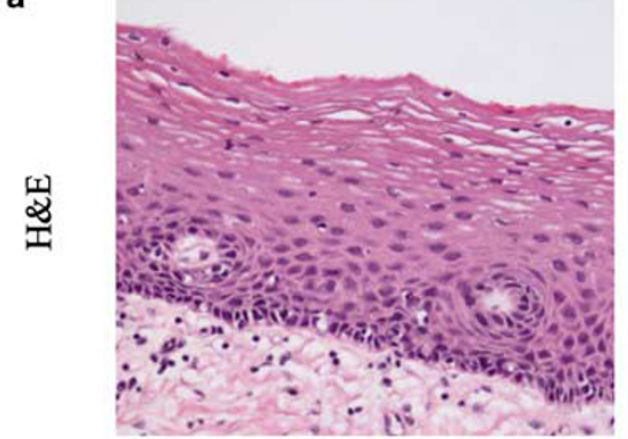

b

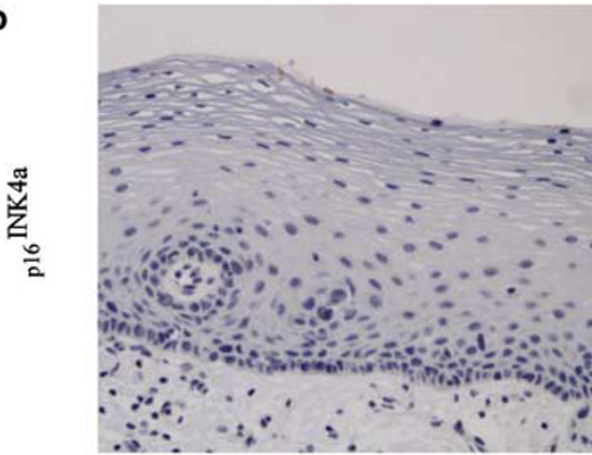

C

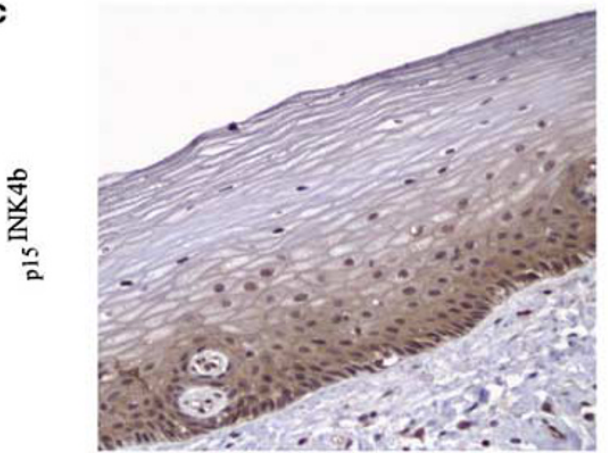

d

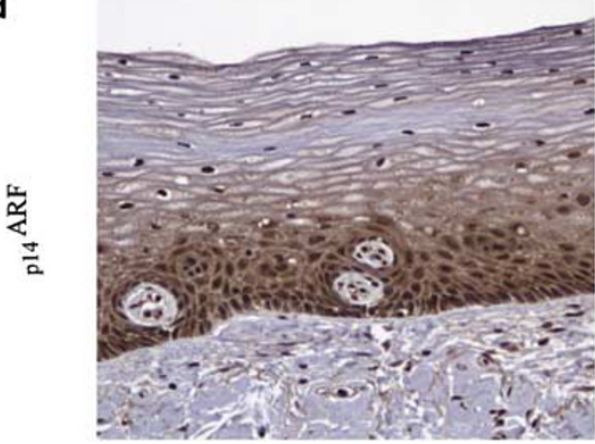

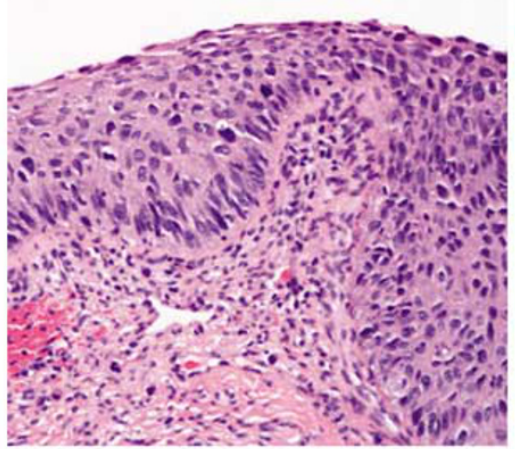
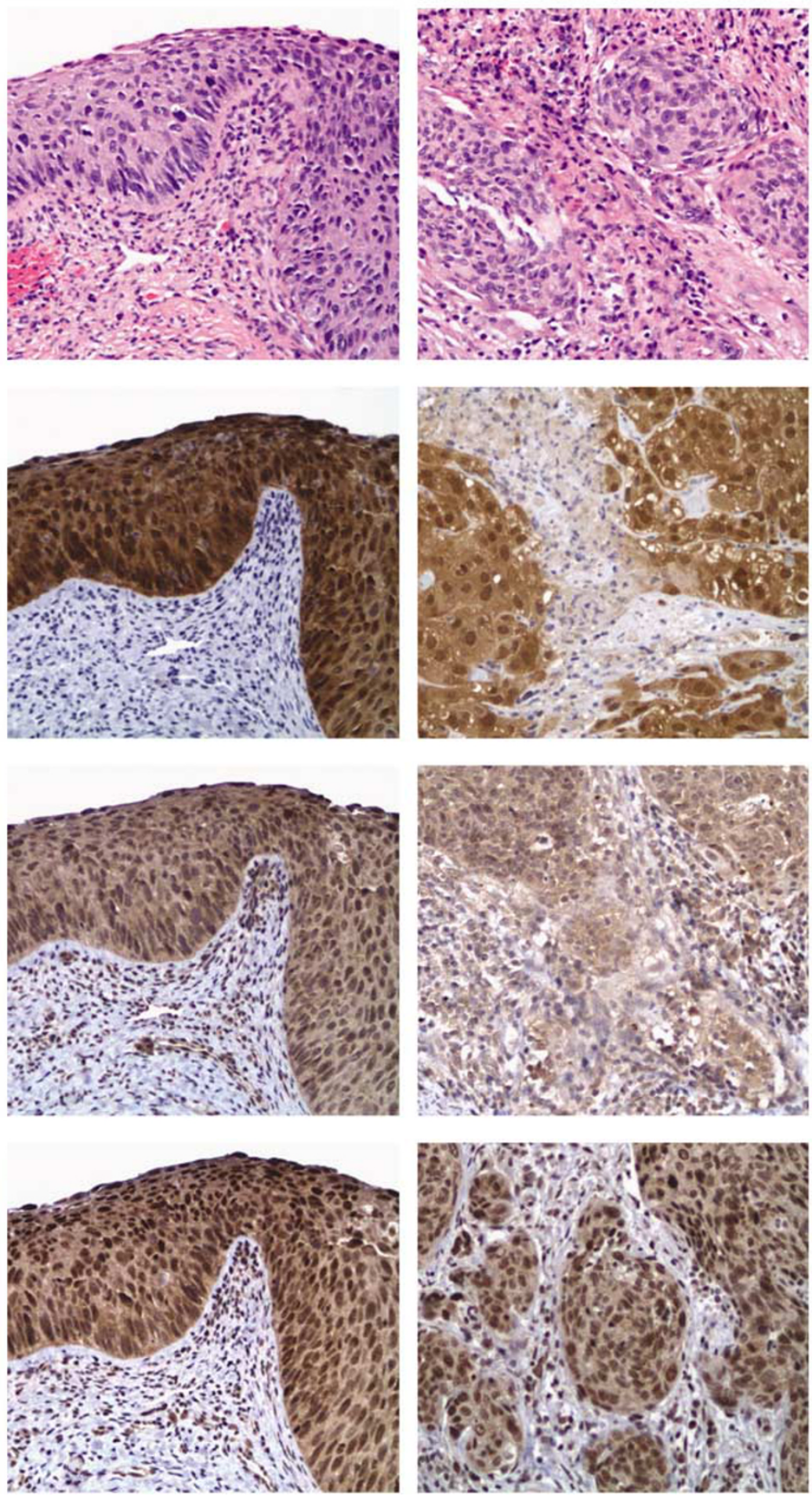

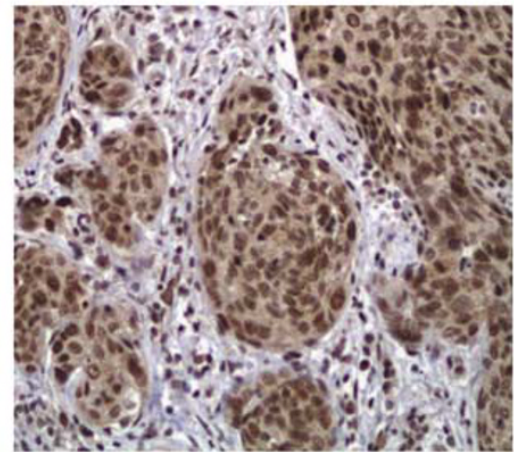

Figure 1 (a) H\&E stain of normal cervix, CIN and SCC. (b) p16 $6^{\mathrm{INK} 4 \mathrm{a}}$ immunostaining showing negative expression in normal cervical epithelium and diffusely strong (2-3) positive expression in most CIN and SCC cases. (c) p15 $5^{\text {INK4b }}$ immunostaining showing weak positive basal expression in normal cervical epithelium and diffusely moderate (1-3) positive expression in most CIN and SCC cases. (d) $\mathrm{p} 14^{\mathrm{ARF}}$ immunostaining showing positive basal expression in normal cervical epithelium; diffusely moderate (1-3) positive expression in some CIN cases and in all SCC cases. 
Table 1 Percentage of cases with expression of senescence markers: p14 ${ }^{\mathrm{ARF}}, \mathrm{p} 15^{\text {INK4b }}$ and $\mathrm{p} 16^{\text {INK4a }}$

\begin{tabular}{|c|c|c|c|c|c|c|c|c|c|}
\hline \multirow{2}{*}{$\begin{array}{l}\text { Staining } \\
\text { intensity }\end{array}$} & \multicolumn{3}{|c|}{$p 16^{I N K 4 a}$} & \multicolumn{3}{|c|}{$p 15^{I N K 4 b}$} & \multicolumn{3}{|c|}{$p 14^{A R F}$} \\
\hline & 0 & $1-2$ & $2-3$ & 0 & $1-2$ & $2-3$ & 0 & $1-2$ & $2-3$ \\
\hline Normal (\%) & 100 & 0 & 0 & 30 & 70 & 0 & 60 & $40^{\mathrm{a}}$ & 0 \\
\hline CIN (\%) & 0 & 15 & 85 & 0 & 70 & 30 & 55 & 10 & 35 \\
\hline SCC (\%) & 5 & 20 & 75 & 5 & 80 & 15 & 0 & 40 & 60 \\
\hline
\end{tabular}

0 : negative; $1-3$ : positive ( 1 is weak and 3 is strong).

Each tissue type consists of 20 specimens.

${ }^{\mathrm{a}}$ Basal/parabasal cell staining only.
Figure 1b). The p15 ${ }^{\mathrm{INK} 4 \mathrm{~b}}$ expression is similar to p16 ${ }^{\mathrm{INK} 4 \mathrm{a}}$ with diffuse but slightly decreased intensity (20/20 CIN and 19/20 SCC specimens show diffuse and 1-3 staining intensity; Figure 1c). The p14 ${ }^{\mathrm{ARF}}$ expression is different in that normal cervical epithelium is only weakly positive $(1+$, confined in basal layer, 8/20) and all SCC show diffuse and strong staining ( $>95 \%, 2-3+$ in $20 / 20$ specimens), while only $9 / 20$ CIN specimens show positive staining with varied intensity and proportion $(1-3+$, $10-95 \%$; Figure 1d). The results of immunostaining for $\mathrm{p} 14^{\mathrm{ARF}}, \mathrm{p} 15^{\mathrm{INK} 4 \mathrm{~b}}$ and $\mathrm{p} 16^{\mathrm{INK} 4 \mathrm{a}}$ of different pathologic lesions are summarized in Tables 1 and 3.
Normal Cervix

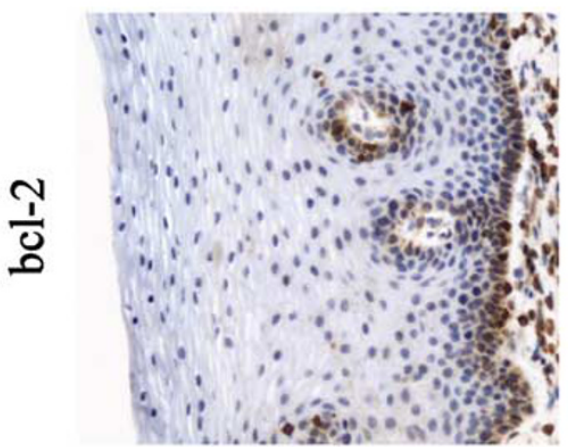

b

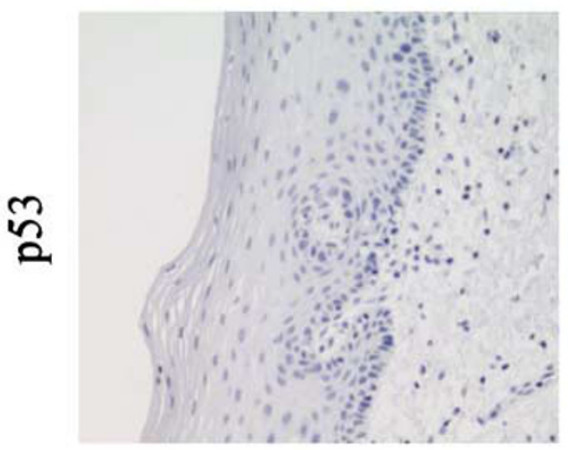

c

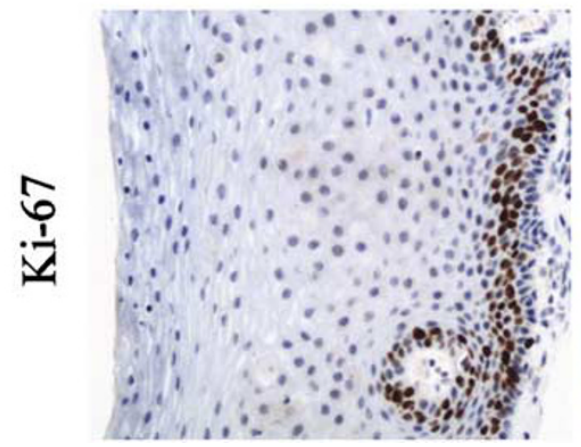

Cervical Dysplasia
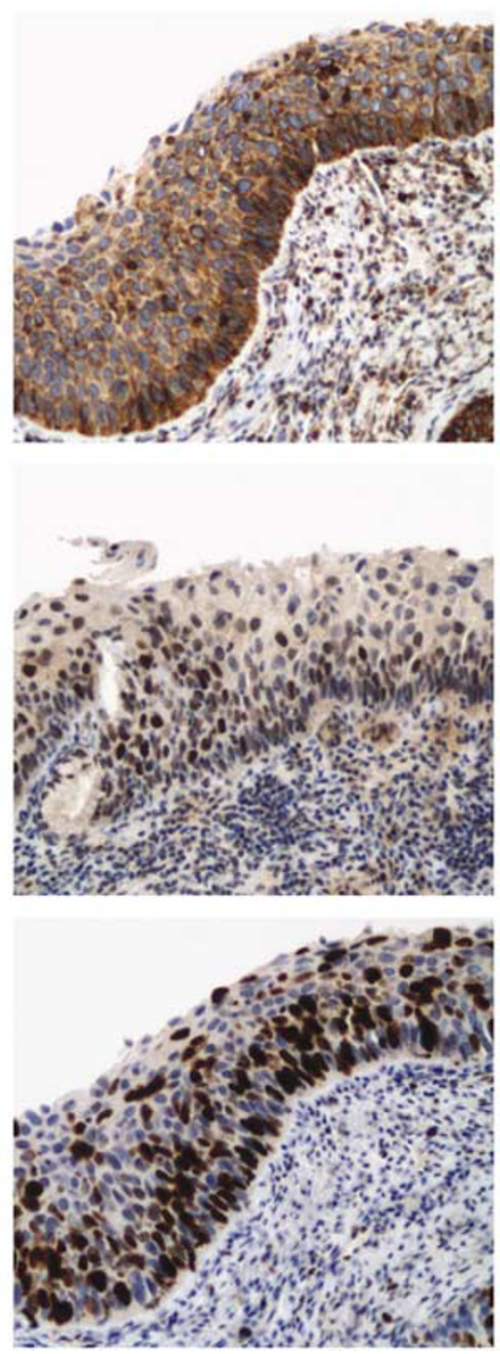

\section{Invasive Squamous Carcinoma}
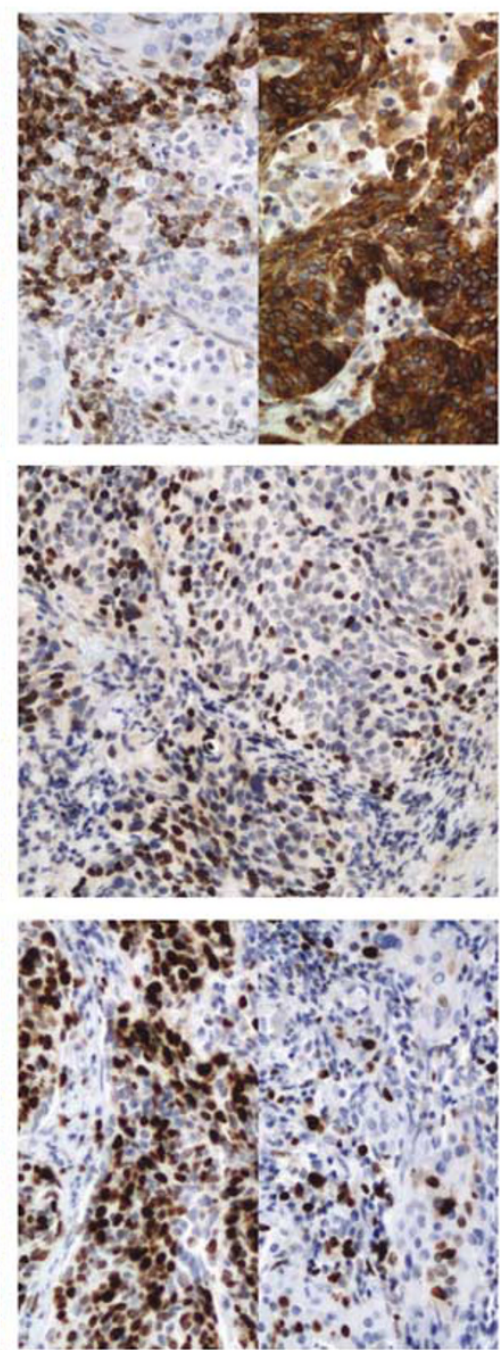

Figure 2 (a) bcl-2 immunostaining showing weak positive cytoplasmic expression confined to basal layer in normal cervical epithelium; positive expression (2-3) in CIN; varied positive expression in some but not all SCC cases. (b) p53 immunostaining showing negative expression in normal cervical epithelium and focal strong (2-3) positive nuclear expression in majority of CIN and SCC cases. (c) Ki-67 immunostaining showing positive basal nuclear expression in normal cervical epithelium; strong (2-3) expression involving middle and upper portion of epithelium in CIN; and proportionally varied but strong (2-3) positive expression in all SCC cases. 
Table 2 Percentage of cases with expression of apoptosis marker: bcl-2; proliferation marker: Ki-67; and p53

\begin{tabular}{|c|c|c|c|c|c|c|c|c|c|}
\hline \multirow{2}{*}{$\begin{array}{l}\text { Staining } \\
\text { intensity }\end{array}$} & \multicolumn{3}{|c|}{ bcl-2 } & \multicolumn{3}{|c|}{$K i-67$} & \multicolumn{3}{|c|}{ p53 } \\
\hline & 0 & $1-2$ & $2-3$ & 0 & $1-2$ & $2-3$ & 0 & $1-2$ & \\
\hline Normal (\%) & 5 & $55^{\mathrm{a}}$ & $35^{\mathrm{a}}$ & 0 & $10^{\mathrm{b}}$ & $90^{\mathrm{b}}$ & 100 & 0 & \\
\hline CIN (\%) & 0 & 35 & 65 & 0 & 0 & 100 & 5 & 15 & 75 \\
\hline SCC (\%) & 55 & 20 & 25 & 0 & 0 & 100 & 0 & 0 & 100 \\
\hline
\end{tabular}

0 : negative; $1-3$ : positive ( 1 is weak and 3 is strong).

Each tissue type consists of 20 specimens.

${ }^{\mathrm{a}}$ Basal cell staining only.

${ }^{\mathrm{b}}$ Parabasal cell staining only.

Table 3 Average percentage of positive staining cells (staining intensity of 1-3) for p14 ${ }^{\mathrm{ARF}}, \mathrm{p} 15^{\mathrm{INK} 4 \mathrm{~b}}, \mathrm{p} 16^{\mathrm{INK} 4 \mathrm{a}}$, bcl-2, Ki-67 and p53 within the CIN/SCC lesion or entire squamous epithelium for normal cervix

\begin{tabular}{lcccccr}
\hline Tissue type & $p 16^{I N K 4 a}$ & $p 15^{I N K 4 b}$ & $p 14^{A R F}$ & $b c l-2$ & Ki-67 & $p 53$ \\
\hline Normal (\%) & 0 & 28 & $11^{\mathrm{a}}$ & $2^{\mathrm{a}}$ & $1.5^{\mathrm{a}}$ & 0 \\
CIN (\%) & 88 & 86 & 40 & 33 & 64 & 16 \\
SCC (\%) & 83 & 72 & 93 & 27 & 76 & 45 \\
\hline
\end{tabular}

Each tissue type consists of 20 specimens.

${ }^{\mathrm{a}}$ Basal cell/parabasal staining only.

The bcl-2 immunostain is weak and confined to basal layer $(1+,<2 \%)$ in $20 / 20$ normal cervical specimens, while its expression is increased in intensity and proportion $(2-3+, 15-95 \%)$ in $20 / 20$ CIN specimens. The expression of bcl-2 in SCC is varied, 9/20 specimens show very strong and diffuse positive staining $(2-3+, 30-100 \%)$, while $11 / 20$ specimens are entirely negative (Figure 2a).

No p53 staining is observed in normal cervical mucosa, while there is focal expression in majority of cervical epithelial dysplasia and cervical carcinoma cases (15/20 CIN and 20/20 SCC specimens show focal and 2-3 staining intensity, see Figure 2b).

Ki-67 is expressed only in isolated parabasal cells in normal cervical epithelium (20/20); its expression in CIN and SCC is strong and more diffuse, involving middle and upper portion of epithelium in 20/20 CIN specimens and diffuse and strong in 20/20 SCC specimens (Figure 2c).

Table 2 summarizes the result of BCL-2, P53 and Ki-67 immunohistochemistry studies and Table 3 shows the average percentage of positive staining cells within the lesion for all of the aforementioned markers.

\section{Discussion}

Two anti-carcinogenic processes, senescence and apoptosis, are constantly at work to keep potential cancer cells from further proliferation. Recent studies have demonstrated the role of senescence in epithelial tumors, including hepatic, pancreatic, lung, skin and prostatic carcinomas, in contrast to prior fibroblast cell culture studies., ${ }^{1,7,18,19}$ Our results suggest while there is increased proliferation in cervical carcinogenesis as reflected in the Ki-67 index, the senescence programs mediated by $\mathrm{p} 15^{\mathrm{INK} 4 \mathrm{~b}}, \mathrm{p} 16^{\mathrm{INK} 4 \mathrm{a}}$ and $\mathrm{p} 14^{\mathrm{ARF}}$ are also activated as reflected in the overexpression of these markers in cervical dysplasia and cervical carcinoma. Since the senescence programs mediated by $\mathrm{p} 15^{\mathrm{INK} 4 \mathrm{~b}}, \mathrm{p} 16^{\mathrm{INK} 4 \mathrm{a}}$ and $\mathrm{p} 14^{\mathrm{ARF}}$ are activated during the dysplasia stage of cervical tumor genesis and remained intact in most squamous carcinomas, other alternative antisenescence pathways may also be disabled. Specifically, our results for $\mathrm{p} 16^{\mathrm{INK} 4 \mathrm{a}}$ and $\mathrm{p} 14^{\mathrm{ARF}}$ confirm previous reports that these markers are overexpressed in cervical carcinomas ${ }^{20-22}$ and are consistent with a compensatory mechanism activated in response to direct interference p53 and pRb by the E6 and E7 HPV oncoproteins.

The apoptotic pathway marker examined here is bcl-2. Although there is the expected gain of bcl-2 expression during carcinogenesis, in cervical dysplasia, there is ultimately a paradoxical loss of bcl-2 expression in approximately half cases of SCCs. Furthermore comparison between CIN cases show that cases with lower level of proliferation had higher level of bcl-2 expression, while cases with higher level of proliferation (Ki-67) are associated with lower level of bcl-2 expression. This similar trend was not readily seen in SCC cases. The loss of bcl-2 was reported previously to be a poor prognostic marker for cervical carcinoma. ${ }^{17}$ This similar phenomenon is also seen in ductal carcinoma of the breast as reported by van Slooten. ${ }^{23}$ In cervical dysplasia, the increased bcl-2 expression may allow survival of the pre-malignant cells as it has been shown that bcl-2 can block p53-mediated G1 arrest apoptosis. ${ }^{24}$ The paradoxical loss of bcl-2 in SCC may also be a response to the direct E6 HPV oncoprotein binding of p53.

The tumor suppressor oncogene, p53, controls entry into the S-phase of the cell cycle and plays many key roles in cell proliferation. It is reported to be lost or mutated in many malignancies; however, reports of p53 in cervical cancers have varied results. Some believe this protein is either degraded or inactivated in cervical cancers, while others report that it is present in majority of SCCs. ${ }^{25}$ In normal tissue this protein is rapidly degraded and undetectable. Our immunohistochemical staining for wild-type and mutant p53 protein showed that p53 is overexpressed in both cervical dysplasia and SCC. One possible explanation is that p53 is inactivated but stabilized by the HPV E6 protein binding, which may also interfere with the normal p53 degradation by MDM2.

The intact senescence pathways mediated by p15 $5^{\text {INK4b }}, \mathrm{p} 16^{\text {INK4a }}$ and p14 ${ }^{\mathrm{ARF}}$, and p53 as well as the varied expression of bcl-2 suggest that cervical 
carcinoma develops as a result of many different mechanisms by which senescence and apoptosis are overridden. The activated senescence pathways examined here also provides an explanation for the delayed nature of SCC development. Although further studies are required to determine the exact role of these senescence and apoptotic markers in cervical carcinogenesis, the consistent overexpression of the senescence marker, p16 ${ }^{\text {INK4a }}$ the proliferation marker, Ki-67, and p53 in dysplasia and carcinoma can effectively augment routine histological diagnostic methods for difficult cases where reactive or atrophic squamous epithelium must be differentiated from dysplasia and invasive carcinoma.

\section{References}

1 Collado M, Gil J, Efeyan A, et al. Tumour biology: senescence in premalignant tumours. Nature 2005; 436:642.

2 Sharpless NE, DePinho RA. Cancer: crime and punishment. Nature 2005;436:636-637.

3 Lowe SW, Cepero E, Evan G. Intrinsic tumour suppression. Nature 2004;432:307-315.

4 Serrano M, Lin AW, McCurrach ME, et al. Oncogenic ras provokes premature cell senescence associated with accumulation of p53 and p16INK4a. Cell 1997;88: 593-602.

5 Kim YT, Zhao M. Aberrant cell cycle regulation in cervical carcinoma. Yonsei Med J 2005;46:597-613.

6 Tsuda H, Hashiguchi Y, Nishimura S, et al. Relationship between HPV typing and abnormality of G1 cell cycle regulators in cervical neoplasm. Gynecol Oncol 2003;91:476-485.

7 Michaloglou C, Vredeveld LC, Soengas MS, et al. BRAFE600-associated senescence-like cell cycle arrest of human naevi. Nature 2005;436:720-724.

8 Stott FJ, Bates S, James MC, et al. The alternative product from the human CDKN2A locus, p14(ARF), participates in a regulatory feedback loop with p53 and MDM2. EMBO J 1998;17:5001-5014.

9 Kroemer G. The proto-oncogene Bcl-2 and its role in regulating apoptosis. Nat Med 1997;3:614-620.

10 Hockenbery D, Nunez G, Milliman C, et al. Bcl-2 is an inner mitochondrial membrane protein that blocks programmed cell death. Nature 1990;348:334-336.

11 Hockenbery DM. The bcl-2 oncogene and apoptosis. Semin Immunol 1992;4:413-420.

12 Agoff SN, Lin P, Morihara J, et al. p16(INK4a) expression correlates with degree of cervical neoplasia: a comparison with Ki-67 expression and detection of high-risk HPV types. Mod Pathol 2003;16: 665-673.
13 Cameron RI, Maxwell P, Jenkins D, et al. Immunohistochemical staining with MIB1, bcl2 and p16 assists in the distinction of cervical glandular intraepithelial neoplasia from tubo-endometrial metaplasia, endometriosis and microglandular hyperplasia. Histopathology 2002;41:313-321.

14 Graflund M, Sorbe B, Karlsson M. Immunohistochemical expression of p53, bcl-2, and p21(WAF1/CIP1) in early cervical carcinoma: correlation with clinical outcome. Int J Gynecol Cancer 2002;12:290-298.

15 Graflund M, Sorbe B, Sigurdardottir S, et al. Relation between HPV-DNA and expression of p53, bcl-2, p21WAF-1, MIB-1, HER-2/neu and DNA ploidy in early cervical carcinoma: correlation with clinical outcome. Oncol Rep 2004;12:169-176.

16 Guimaraes MC, Goncalves MA, Soares CP, et al. Immunohistochemical expression of p16INK4a and bcl-2 according to HPV type and to the progression of cervical squamous intraepithelial lesions. J Histochem Cytochem 2005;53:509-516.

17 Munakata S, Watanabe O, Ohashi K, et al. Expression of Fas ligand and bcl-2 in cervical carcinoma and their prognostic significance. Am J Clin Pathol 2005;123: 879-885.

18 Zhang Z, Rosen DG, Yao JL, et al. Expression of p14(ARF), p15(INK4b), p16(INK4a), and DCR2 increases during prostate cancer progression. Mod Pathol 2006;19:1339-1343.

19 Jin M, Piao Z, Kim NG, et al. p16 is a major inactivation target in hepatocellular carcinoma. Cancer 2000;89: 60-68.

20 Kanao H, Enomoto T, Ueda Y, et al. Correlation between $\mathrm{p} 14(\mathrm{ARF}) / \mathrm{p} 16(\mathrm{INK} 4 \mathrm{~A})$ expression and HPV infection in uterine cervical cancer. Cancer Lett 2004;213:31-37.

21 Sano T, Oyama T, Kashiwabara K, et al. Immunohistochemical overexpression of p16 protein associated with intact retinoblastoma protein expression in cervical cancer and cervical intraepithelial neoplasia. Pathol Int 1998;48:580-585.

22 Sano T, Masuda N, Oyama T, et al. Overexpression of p16 and p14ARF is associated with human papillomavirus infection in cervical squamous cell carcinoma and dysplasia. Pathol Int 2002;52:375-383.

23 van Slooten HJ, van d V, van d V, et al. Loss of Bcl-2 in invasive breast cancer is associated with high rates of cell death, but also with increased proliferative activity. Br J Cancer 1998;77:789-796.

24 Ryan JJ, Prochownik E, Gottlieb CA, et al. c-myc and bcl-2 modulate p53 function by altering p53 subcellular trafficking during the cell cycle. Proc Natl Acad Sci USA 1994;91:5878-5882.

25 Troncone G, Martinez JC, Palombini L, et al. Immunohistochemical expression of mdm2 and p21WAF1 in invasive cervical cancer: correlation with p53 protein and high risk HPV infection. J Clin Pathol 1998;51: 754-760. 